\title{
Antiviral activity of porcine interferon delta 8 against foot-and-mouth disease virus in vitro
}

\author{
Shi-fang Li $^{\mathrm{a}, \mathrm{b}}$, Jun-jun Shao ${ }^{\mathrm{a}, \mathrm{b}}$, Fu-rong Zhao ${ }^{\mathrm{a}, \mathrm{b}}$, Mei-jiao Gong ${ }^{\mathrm{a}, \mathrm{c}}$, Yin-li Xie ${ }^{\mathrm{a}, \mathrm{b}}$, Hui-yun Chang, ${ }^{\mathrm{a}, \mathrm{b}, *}$, \\ Yong-guang Zhang ${ }^{\mathrm{a}, \mathrm{b}, *}$ \\ ${ }^{\text {a }}$ State Key Laboratory of Veterinary Etiological Biology, OIE/National Foot-and-Mouth Disease Reference Laboratory, Lanzhou Veterinary Research Institute, Chinese \\ Academy of Agricultural Sciences, Lanzhou 730046, Gansu, PR China \\ ${ }^{\mathrm{b}}$ Jiangsu Co-innovation Center for Prevention and Control of Important Animal Infectious Diseases and Zoonoses, Yangzhou, Jiangsu Province 225009, PR China \\ ${ }^{\mathrm{c}}$ College of Veterinary Medicine, Gansu Agricultural University, Lanzhou 730070, PR China
}

\section{A R T I C L E I N F O}

\section{Keywords:}

Type I interferon

Porcine interferon-delta

Antiviral activity

FMDV

\begin{abstract}
A B S T R A C T
Foot-and-mouth disease (FMD) is one of the most devastating diseases affecting livestock. Since vaccines fail to provide protection until seven days post-vaccination, the application of anti-viral molecules is imperative for suppressing the spread of FMDV prior to development of an adaptive immune response. Interferons (IFNs) are effective for the host to fight FMDV infections; however, a novel type I IFNs, interferon delta (IFN- $\delta$ ), has not been investigated for their antiviral effects against this virus. Thus, this study investigated FMDV infection, upon pre- and post-treatment with PoIFN- $\delta 8$. Real-time quantitative PCR was used to quantify the expression levels of IFN-stimulated genes (ISGs), including ISG15, OAS1, PKR, and Mx1. Results showed the PoIFN- $\delta 8$ lacking its signal sequence was efficiently expressed in Escherichia coli, and the purified recombinant PoIFN- $\delta 8$ exerted a significantly protective effect against two different serotypes of FMDV in IBRS- 2 cells. In addition, PoIFN- $\delta 8$ induced the expression of IFN-stimulated genes. These findings highlight the significance of PoIFN- $\delta$ might serve as an antiviral agent for the prevention of FMDV in pigs and will stimulate the study of exploiting the potential biological functions of IFN- $\delta$ in the future.
\end{abstract}

\section{Introduction}

Interferons (IFNs) are the first line of defense against viral infections. There are three groups of IFNs (type I, II and III) based on differences in the structure of their cell surface receptors [1]. Type I IFNs are the largest family and are the prominent IFNs responding to viral infections. In spite of this, studies of type I IFNs are still mainly focused on IFN- $\alpha$ and $\beta$, while knowledge of other subtypes is limited. As one of the members of type I IFNs, IFN- $\delta$ was first identified by Lefevre and Boulay in 1993 [2]. Subsequently, Cochet et al. reported several IFN- $\delta$ related sequences by genomic database screening and indicated that IFN- $\delta$ exists in numerous cloven-hoofed animals and form a distinct cluster in the genome [3]. Expressing in the porcine blastocyst during implantation, IFN- $\delta$ was suggested have specific functions during pregnancy $[2,4,5]$. Similar to other type I IFNs, which bind to type I interferon receptors and activate the Jak-STAT pathway to produce antiviral proteins, the mRNA expression of IFN- $\delta$ is upregulated upon viral infection by the same mechanism [6]. IFN- $\delta$ has been demonstrated to have antiviral activity against Pseudorabies Virus (PRV),
Vesicular Stomatitis Virus (VSV), and Porcine reproductive and respiratory syndrome virus (PRRSV) [6,7].

Different porcine interferon (PoIFN)- $\delta$-related subtypes show distinct antiviral activities. The difference in these activities is likely caused by the structure of the protein. For example, an unstable 4- $\alpha$ helix barrel can impair the function of IFN- $\delta$. Among the three PoIFN- $\delta$ subtypes, which include PoIFN- $\delta 4$, PoIFN- $\delta 5$, and PoIFN- $\delta 8$, the PoIFN$\delta 8$ has the strongest antiviral and immunomodulatory activities [6]. In addition, researchers revealed that the porcine IFN- $\delta$ family comprises a large number of members and the inner diversity is bigger than PoIFN- $\alpha$ and PoIFN- $\omega$ families [6]. This phenomenon indicates their biological importance, and it is prudent to explore whether IFN- $\delta$ could serve as a therapeutic candidate, or alternative to other interferons for the treatment of various viral diseases, such as foot and mouth disease (FMD).

Foot-and-mouth disease is an economically important and highly contagious disease in cloven-hoofed animals, including cattle, swine, and sheep [8]. The etiological agent, namely FMDV, is a prototypical member of the Aphthovirus genus of the family, Picornaviridae. However, this virus exists in seven serotypes (namely A, O, C, Asia1, SAT1,

\footnotetext{
* Corresponding authors at: State Key Laboratory of Veterinary Etiological Biology, National, Foot-and-Mouth Diseases Reference Laboratory, Lanzhou Veterinary Research Institute, Chinese Academy of Agricultural Sciences, Lanzhou 730046, PR China.

E-mail addresses: changhuiyun@caas.cn (H.-y. Chang), zhangyongguang@caas.cn (Y.-g. Zhang).
} 
SAT2, and SAT3) and multiple subtypes that do not cross-protect against each other, making it difficult to effectively control the disease $[9,10]$. Given its antigenic variability, the use of FMD vaccines to protect early infection is limited. Therefore, an alternative strategy of applying antiviral agents is required to control the spread of FMDV during outbreaks. In recent years, the World Organization for Animal Health (OIE) has suggested that an effective disease control program should use newly developed vaccines alongside antiviral or immunomodulatory agents [11]. Herein, PoIFN- $\delta 8$ was expressed and purified in a prokaryotic expression system, and its in vitro antiviral activity against FMDV was investigated using IBRS-2 cells.

\section{Materials and methods}

\subsection{Cells and viruses}

The FMDVs (O/MYA98/BY/2010 and A/GD/MM/2013) were preserved and provided by OIE/National Foot-and-Mouth Disease Reference Laboratory of China. Swine kidney cells (IBRS-2) were purchased from CCTCC (China Center for Type Culture Collection) and then maintained in our laboratory. IBRS-2 cells were cultured in Dulbecco's Modified Eagle Medium (DMEM) (Gibco, Grand Island, NY) containing $10 \%$ fetal bovine serum (FBS) at $37{ }^{\circ} \mathrm{C}$ and $5 \% \mathrm{CO}_{2}$. Escherichia coli (E. coli) Rosetta (DE3) Lys cells were used for expression of PoIFN- $\delta 8$. The TCID 50 of FMDV was calculated according to the Reed and Muench method [12].

\subsection{Cloning, expression and purification of PoIFN- $\delta 8$}

The PoIFN- $\delta 8$ gene (Gene accession GQ415081) lacking the signal sequence was codon-optimized for Escherichia coli expression (the optimized sequence is listed in S1) and synthesized by Shanghai Sangon Biotechnology Co., Ltd. (Shanghai, China). The vector containing the target gene flanked by EcoRI and Hind III restriction sites, was digested with the corresponding enzymes and ligated into the same sites in a pET-30a expression vector (Novagen, Corporation, CA, USA) to generate pET30a-PoIFN- $\delta 8$. The gene contained an $\mathrm{N}$-terminal His tag to facilitate protein purification. The positive pET30a-PoIFN- $\delta 8$ clone was induced with isopropyl $\beta$-D-thiogalactoside (Sigma, USA) in E. coli Rosetta (DE3) Lys cells until the optical density (OD) at $600_{\mathrm{nm}}=0.4-0.6$. After that time, growth continued for an additional $8 \mathrm{~h}$. Subsequently, whole cells were collected and sonicated (at $200 \mathrm{~W}$, $2 \mathrm{~s}$ on and $2 \mathrm{~s}$ off) until the solution became clear. Supernatants and sedimentations were then isolated by centrifugation. The inclusion bodies were resuspended in Buffer $\mathrm{A}(8 \mathrm{M}$ urea, $2 \mathrm{mM} \beta$-mercaptoethanol, $20 \mathrm{mM}$ Tris- $\mathrm{HCl}, 100 \mathrm{mM} \mathrm{NaH} \mathrm{PO}_{2} \cdot 2 \mathrm{H}_{2} \mathrm{O} \mathrm{pH}=8.0$ ), and incubated at $4{ }^{\circ} \mathrm{C}$ for $16 \mathrm{~h}$. Subsequently, the soluble protein was then purified by Ni-NTA affinity chromatography using an AKTA purifier FPLC (GE Healthcare), according to the manufacturer's instructions. Briefly, the resuspended inclusion bodies was mixed with Ni-NTA agarose matrix pre-equilibrated with Binding buffer $(20 \mathrm{mM}$ Tris- $\mathrm{HCl}$, $100 \mathrm{mM} \mathrm{NaH} \mathrm{PO}_{4} \cdot 2 \mathrm{H}_{2} \mathrm{O}, 6 \mathrm{M}$ Urea, $\mathrm{pH} 8.0$ ), and then mixed gently by shaking at $4{ }^{\circ} \mathrm{C}$ for $3 \mathrm{~h}$. The lysate- $\mathrm{Ni}^{2+}$-NTA mixture was loaded onto a column, and the column was then washed with Wash buffer $(20 \mathrm{mM}$ Tris-HCl, $100 \mathrm{mM} \mathrm{NaH}_{2} \mathrm{PO}_{4} \cdot 2 \mathrm{H}_{2} \mathrm{O}, 6 \mathrm{M}$ Urea, $80 \mathrm{mM}$ imidazole, $\mathrm{pH}$ 8.0). Finally, the bound protein was eluted with Elution buffer (20 mM Tris$\mathrm{HCl}, 100 \mathrm{mM} \mathrm{NaH} \mathrm{PO}_{4} \cdot 2 \mathrm{H}_{2} \mathrm{O}, 6 \mathrm{M}$ Urea, $500 \mathrm{mM}$ imidazole, $\mathrm{pH}$ 8.0). Next, the purified protein was renatured through dialysis with buffer (100 mM Tris, 2 mM EDTA, 1\% Glycine, 5\% Glycerinum, pH 8.0) under a urea gradient to reduce the concentration from $4 \mathrm{M}$ to $0 \mathrm{M}$. After denaturation and renaturation, soluble homogeneous protein was obtained and the concentration was quantified using the Bradford Protein Assay kit (Beyotime, Shanghai China), according to the manufacturer's instructions. Endotoxin levels of the purified PoIFN- $\delta 8$ protein were evaluated with Genscript ToxinSensor ${ }^{\mathrm{TM}}$ Chromogenic LAL Endotoxin Assay Kit (New Jersey, USA) as described by the manufacturer.

\subsection{Western blotting}

Western blot was employed to confirm the expression of the HisPoIFN- $\delta 8$. Briefly, $20 \mu \mathrm{g}$ of recombinant His-PoIFN- $\delta 8$ was subjected to $12 \%$ sodium dodecyl sulfate polyacrylamide gel electrophoresis (SDSPAGE), followed by transfer to PVDF membranes and blocking with 5\% $(\mathrm{w} / \mathrm{v})$ nonfat milk for $1 \mathrm{~h}$ at room temperature (RT). After washing three times with Tris-buffered saline-Tween solution (TBST), the membranes were incubated with anti-poly histidine antibody (Sigma) (diluted at $1: 4000$ ) overnight at $4^{\circ} \mathrm{C}$. After washing three times with TBST, the membranes were incubated in rabbit anti-mouse His (ZSGB, Beijing, China, diluted at 1:5000) for $1 \mathrm{~h}$ at RT. After being washed three times in TBST, the ECL and a chemiluminescence kit were used for imagining (Millipore Corporation, Billerica, MA, United States).

\subsection{Anti-viral activities of pre- and post-treatment with PoIFN- $\delta 8$ in IBRS-2 cells}

IBRS- 2 cells were added to each well of a 96-well plate at a density of $3.5 \times 10^{4}$ cells/well ( $80 \%$ confluence). Two types of anti-viral methods were used to investigate the effectiveness of PoIFN- $\delta 8$. In the first method, cells were treated with a 10 -fold serial dilution of PoIFN$\delta 8$ for $24 \mathrm{~h}$ and then infected with 100 TCID $_{50}$ FMDV O/MYA98 for $1 \mathrm{~h}$ (pre-treatment). The IBRS-2 cells were incubated at $37^{\circ} \mathrm{C}$ and $5 \% \mathrm{CO}_{2}$ in an incubator for $48 \mathrm{~h}$ until the maximum CPE of FMDV was reached. In the second method, cells were infected with $100 \mathrm{TCID}_{50}$ FMDV O/ MYA98 for $1 \mathrm{~h}$ and then treated with $2000 \mathrm{ng} / \mathrm{ml}$, which was the lowest concentration that provided $100 \%$ protection against CPE in the abovementioned concentration determination study at various time intervals $(0,2,4,8,16$, and $24 \mathrm{~h})$ (post-treatment). Untreated control wells (cell control and virus control) were also maintained along with the treated cells. When the virus control wells showed 100\% CPE, the supernatants were removed and the cells were added to MTS assay solution to detect the level of viability of the infected cells using the CellTiter 96 AQueous One Solution Proliferation Assay (Promega, USA). Quantitative realtime RT-PCR with specific primers (FF: 5'-CCCAGGGCCACCACATAG-3' and FR: 5'-AGCTTGTACCAGGGTTTGGC-3') was used to measure the relative viral mRNA expression levels in treated (test) and untreated (control) wells. $\beta$-Actin ( $\beta$-actin-F-5'-GACCACCTTCAACTCGATCA-3' and $\beta$-actin-R-5'-GTGTTGGCGTAGAGGTCCTT- $3^{\prime}$ ) was used as the reference gene.

\subsection{Antiviral activity of PoIFN- $\delta 8$ against different strain of FMDV}

A pilot study was conducted according to the method described by Usharani et al. [13] to calculate the optimal concentration of IFN pretreatment needed to protect cells from CPE prior to infection with different strains of FMDV. In this study, IBRS-2 cells were treated with different concentrations of PoIFN- $\delta 8$ (1000, 2000, 3000, and $4000 \mathrm{ng} /$ $\mathrm{ml}$ ) for $24 \mathrm{~h}$ and were subsequently infected with $100 \mathrm{TCID}_{50}$ of FMDV $\mathrm{A} / \mathrm{GD} / \mathrm{MM} / 2013$. The cell viability and viral mRNA levels were assessed as described above.

\subsection{Evaluation IFN-stimulated genes (ISGs) expression in IBRS-2 cells}

In order to elucidate the mechanism of PoIFN- $\delta 8$ antiviral efficacy, IFN-stimulated genes (ISGs) expression in IBRS-2 cells were investigated by real time PCR. Briefly, IBRS-2 cells were plated on 12-well plates at a density of $3.5 \times 10^{5}$ per well and grown until $90 \%$ confluent. And then, the cells were treated with $2000 \mathrm{ng} / \mathrm{ml}$ of PoIFN- $\delta 8$ for $24 \mathrm{~h}$, untreated cells as control group. Inocula were then removed, and cells were washed twice with DMEM. Subsequently total cellular RNA was extracted using the RNA Extraction Kit (Tiangen, Beijing, China) and reverse-transcribed to cDNA with RT primer Mix provided in the PrimeScriptTM RT reagent kit containing gDNA Eraser (Takara, Dalian, China). Real-time PCR was used to analyse the expressions of ISG genes 
(including Mx1, ISG15, PKR, OAS) on an Agilent Technologies Stratagene Mx3005P instrument (Agilent, USA) using SYBR Premix Ex TaqTM II (Tli RNaseH Plus) (TaKaRa, Dalian, China). The following primer sets were used for real-time PCR: porcine PKR forward, 5'-AAAGCGGACAAGTCGAAAGG-3'; porcine PKR reverse, 5'-TCCACTT CATTTCCATAGTCTTCTGA-3'; porcine OAS forward, 5'-GAGCTGCAG CGAGACTTCCT-3'; porcine OAS reverse, 5'-TGCTTGACAAGGCGGA TGA-3'; porcine Mx1 forward, 5'-GGCGTGGGAATCAGTCATG-3'; porcine Mx1 reverse, 5'-AGGAAGGTCTATGAGGGTCAGATCT-3'; porcine ISG15 forward, 5'-GCCCTCTCCAGTGCCCGG-3'; porcine ISG15 reverse, 5'-CCCAGGGCCACCACATAG-3'. $\beta$-Actin was used as the reference gene [14]. Real-time PCR reactions were performed in a total volume of $25 \mu \mathrm{L}$ containing template cDNA, forward and reverse primers, and $2 \times$ SYBR Premix Ex Taq (TaKaRa). The mRNA levels of ISG genes in PoIFN88-treated cells or untreated cells were normalized to that of porcine $\beta$-actin mRNA. Three independent experiments were performed, and the average of the normalized values were presented.

\subsection{Statistical analysis}

The relative mRNA expression was calculated using the $2^{-\Delta \Delta C T}$ method. All the graphical illustrations were conducted by GraphPad Prism software. The significance of the differences was determined by the $t$-test and one-way ANOVA using the SPSS software, followed by Tukey's post-hoc multiple comparison test. All data are reported as means \pm standard deviation $(\mathrm{n} \geq 3)$. Values of $p<0.05$ were considered statistically significant.

\section{Results}

\subsection{Cloning and purification of PoIFN- $\delta 8$}

In order to achieve a high protein yield, the nucleotide sequence of the IFN- $\delta 8$ gene was optimized using high-usage $E$. coli codons. The codon-optimized sequence was ligated into the expression vectors, and recombinant plasmids were constructed (Fig. 1) and verified by DNA sequencing (data not shown). The recombinant plasmid was then transformed into E. coli Rosetta (DE3) Lys cells for expression. SDSPAGE analysis revealed that recombinant PoIFN- $\delta 8$ was mainly expressed as inclusion bodies, which exhibited a molecular weight of

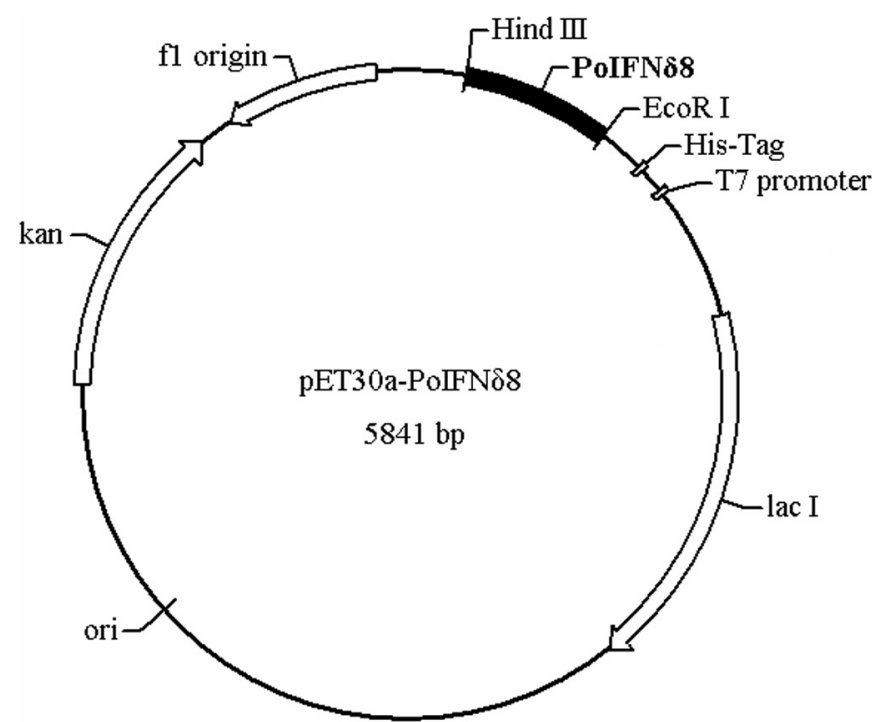

Fig. 1. Recombinant pET30a-PoIFN- $\delta 8$ plasmid construction. The PoIFN- $\delta 8$ sequence was inserted into the vectors at the EcoRI and Hind III restriction sites. Plasmid pET30a-PoIFN- $\delta 8$ consisted of a His tag and the mature PoIFN- $\delta 8$ sequence.
$22.87 \mathrm{kDa}$ (Fig. 2A). Over $90 \%$ purity of rHis-PoIFN- $\delta 8$ protein was obtained following purification with a Ni-NTA agarose (IMAC) column (Fig. 2A) and the protein was confirmed by western blot analysis using an anti-histidine monoclonal antibody (Fig. 2B). The concentration of the purified PoIFN- $\delta 8$ was $793.6 \mu \mathrm{g} / \mathrm{ml}$, while the endotoxin level of the protein was assayed using the Genscript ToxinSensor ${ }^{\mathrm{TM}}$ Chromogenic LAL Endotoxin Assay Kit (New Jersey, USA) and found to be lower than $0.01 \mathrm{EU} / \mathrm{ml}$.

\subsection{Antiviral activity of PoIFN- $\delta 8$}

To evaluate the minimum antiviral protection concentration of PoIFN- $\delta 8$ for IBRS- 2 cells, PoIFN- $\delta 8$ was serially diluted ten-fold from 2000 to $0.02 \mathrm{ng} / \mathrm{ml}$ and five replicates were added to naïve cells. The cells were challenged with FMDV O/MYA98 $24 \mathrm{~h}$ post-PoIFN- $\delta 8$ treatment. The highest dilution of PoIFN- $\delta 8$ to protect IBRS- 2 cells from FMDV-induced CPE was $2000 \mathrm{ng} / \mathrm{ml}$, which showed $100 \%$ protection. Other dilutions of PoIFN- $\delta 8$ tested did not confer protection to the cells from CPE caused by FMDV O/MYA98 (Fig. 3A). There was a significant difference in the CPE effect between the $2000 \mathrm{ng} / \mathrm{ml}$ group and the other concentration and virus control groups $(p<0.01)$. A concentration of $2000 \mathrm{ng} / \mathrm{ml}$ reduced viral mRNA levels by 4.63-log titers, compared to virus controls (Fig. 3B). To evaluate whether PoIFN- $\delta 8$ could prevent CPE of cells following viral infection, the antiviral efficacy of PoIFN- $\delta 8$ was evaluated at various intervals post-FMDV infection. IBRS- 2 cells were infected with FMDV O/MYA98 at various time intervals $(0,2,4,8,16$ and $24 \mathrm{~h})$ and treated with $2000 \mathrm{ng} / \mathrm{ml}$ of PoIFN$\delta 8$, which was the lowest concentration that provided $100 \%$ protection against CPE. PoIFN- $\delta 8$ demonstrated $100 \%$ protection against FMDVinduced CPE for up to $8 \mathrm{~h}$ post-infection (Fig. 4A) and showed a 4.17$\log$ to $4.85-\log$ reduction in viral mRNA levels at 0,2 , and $4 \mathrm{~h}$ postinfection, compared to virus controls (Fig. 4B) $(p<0.01)$. However, no protection was observed against CPE and viral mRNA levels were not decreased at $16 \mathrm{~h}$ or $24 \mathrm{~h}$ post-FMDV infection (Fig. 4B), compared to $\mathrm{CPE}$ and viral mRNA levels, respectively, in the non-treated group (Non-tr) $(p>0.05)$.

\subsection{Antiviral activity of PoIFN- $\delta 8$ against type A FMDV}

To investigate the potential broad-spectrum antiviral activity of PoIFN- 88 , IBRS- 2 cells was pre-treated with different concentrations of PoIFN- $\delta 8$ for $24 \mathrm{~h}$. Cells were then infected with 100 TCID $_{50}$ FMDV A/ $\mathrm{GD} / \mathrm{MM} / 2013$. PoIFN- $\delta 8(1000 \mathrm{ng} / \mathrm{ml})$ showed at or near $100 \%$ prevention of CPE caused by type A FMDV (Fig. 5).

\subsection{PoIFN- 88 -induced expression of ISGs}

Type I IFNs exhibit antiviral activity by binding specific receptors and stimulating hundreds of downstream ISG genes. PoIFN- $\delta 8$ also induced the expression of Mx1, ISG15, PKR and OAS1 genes by 149.17fold, 119.16-fold, 3.7-fold and 328-fold, respectively, compared to cells without IFN treatment (Fig. 6).

\section{Discussion}

Generally, IFNs constitute the first step in the immune response against viral infection, and have been used to fight cancer or viral infections. In terms of FMDV, previous studies demonstrated that type I IFNs (including IFN- $\alpha, \beta, \tau)$, IFN- $\gamma$ and IFN- $\lambda$ had certain antiviral activities against FMDV $[11,13,15,16]$. In our recent study, we demonstrated that IFN- $\omega$ had antiviral activities against foot and mouth disease virus (unpublished). However, interferon delta, which is a type I IFN, has never been investigated in this capacity. This is the first study to assess the anti-FMDV activity of PoIFN- $\delta$ in cells using MTS assays and RT-PCR to evaluate the reduction in cytopathic effects and viral mRNA levels after FMDV infection. Similar to the case in IFN- $\omega$, 

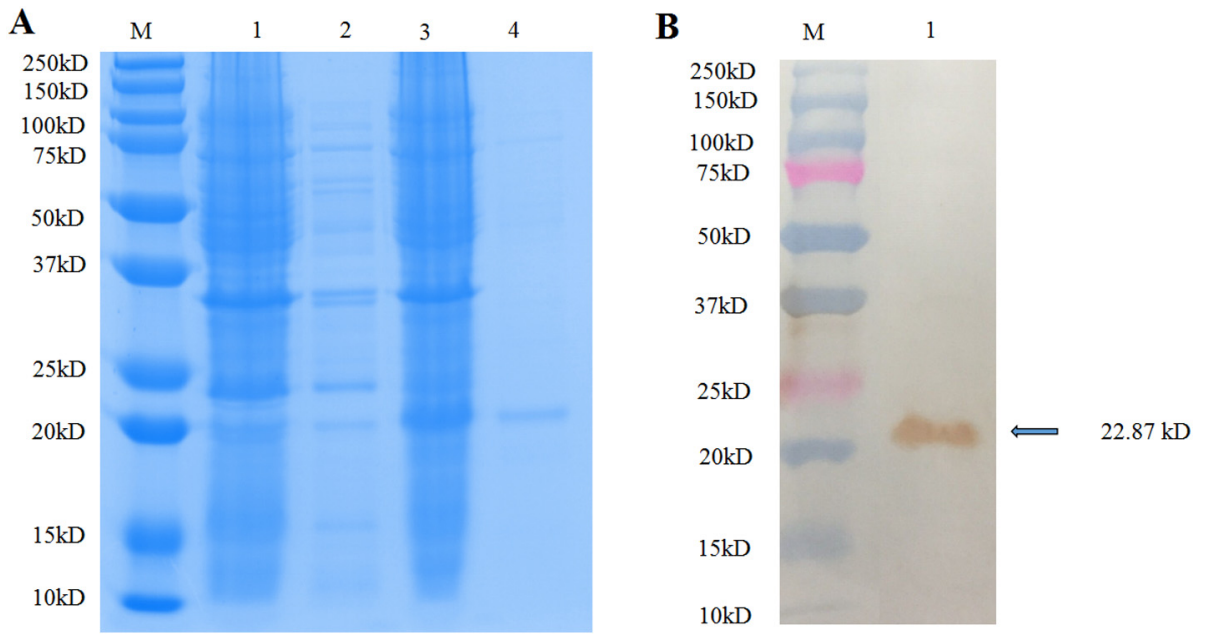

Fig. 2. A. SDS-PAGE analysis of PoIFN- $\delta 8$ expression: Lane M: Protein marker; Lane 1: Uninduced control; Lane 2: Induced protein in soluble fraction; Lane 3: Induced protein in inclusion bodies; Lane 4: Purified and dialyzed PoIFN- $\delta 8$. 2B. Western blot confirmation of PoIFN- $\delta 8$ using anti-polyhistidine monoclonal antibody. Lane M: Protein marker; Lane 1: Purified PoIFN- $\delta 8$ protein.
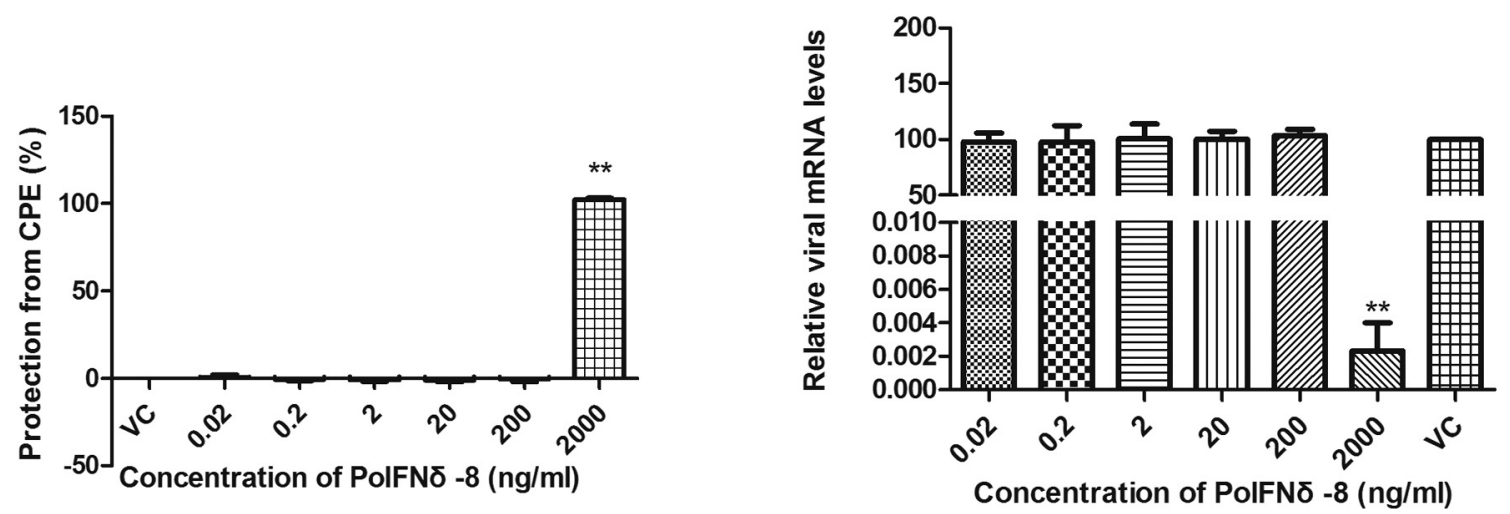

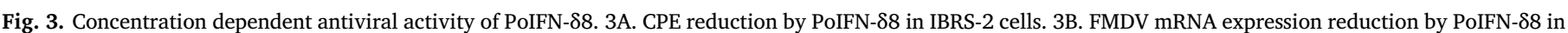

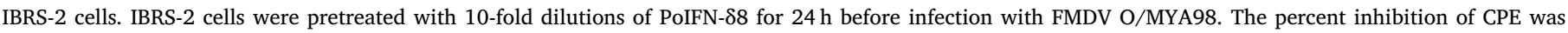

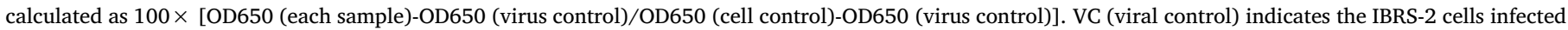

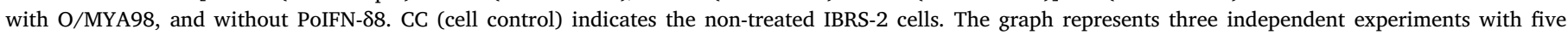

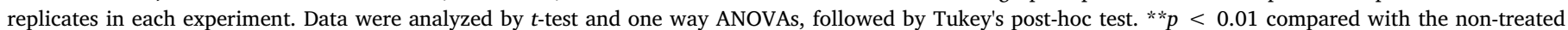
control.

A

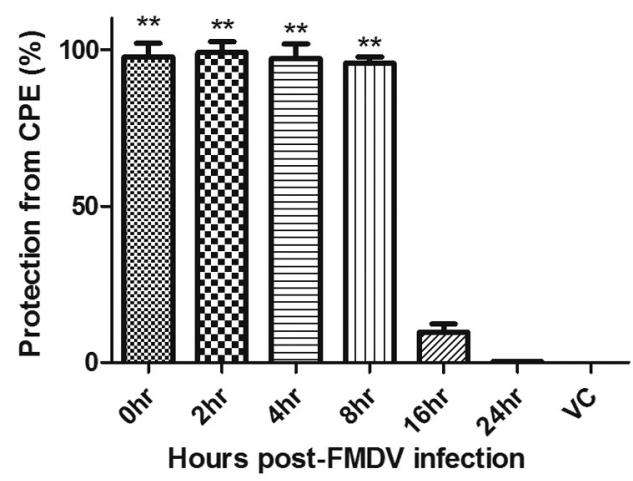

B

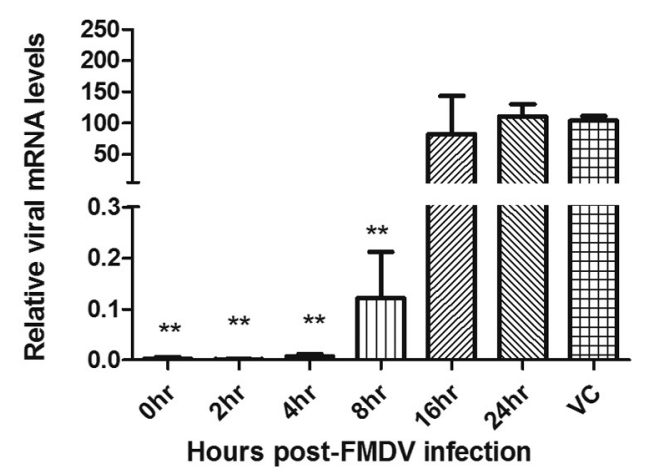

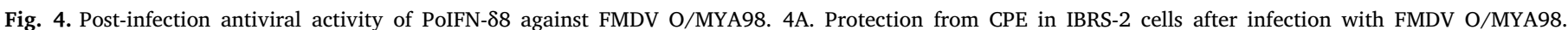

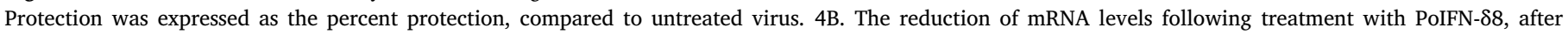

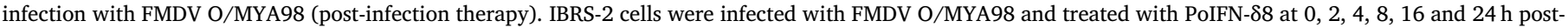

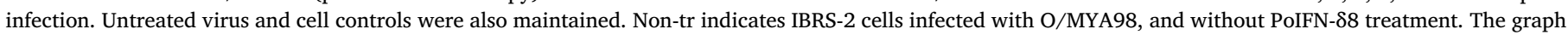

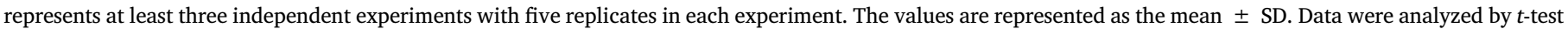
and one way ANOVAs, followed by Tukey's post-hoc test. ${ }^{* *} p<0.01$ compared with the control group. 
A

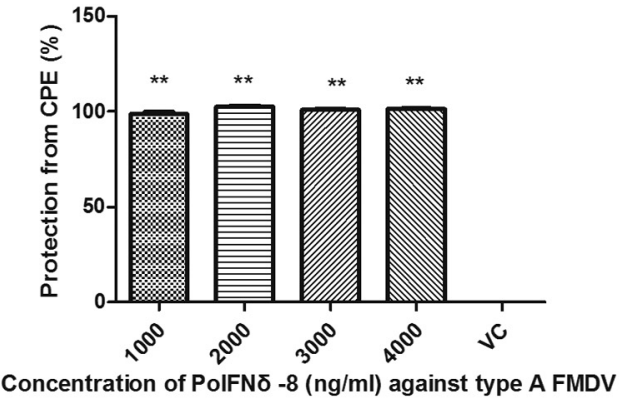

B

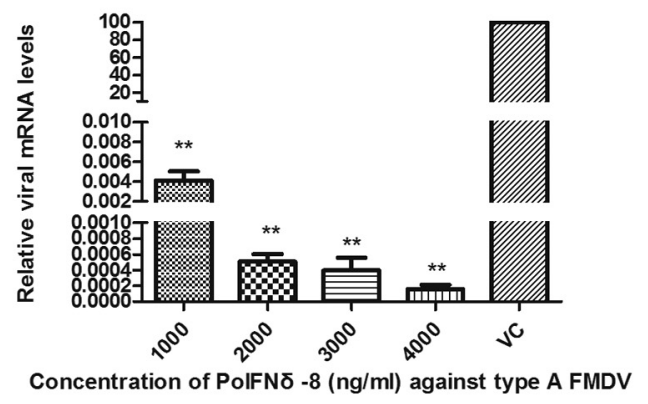

Fig. 5. Antiviral efficacy of PoIFN- $\delta 8$ against type A FMDV. 5A. CPE protection assay to evaluate the effectiveness of PoIFN- $\delta 8$ against type A FMDV. $5 B$. FMDV mRNA reduction assay. The graph represents three independent experiments with five replicates in each experiment. The values are represented as the mean \pm SD. Data were analyzed by $t$-test and one way ANOVAs, followed by Tukey's post-hoc test, ${ }^{* *} p<0.01$ compared with the control group.

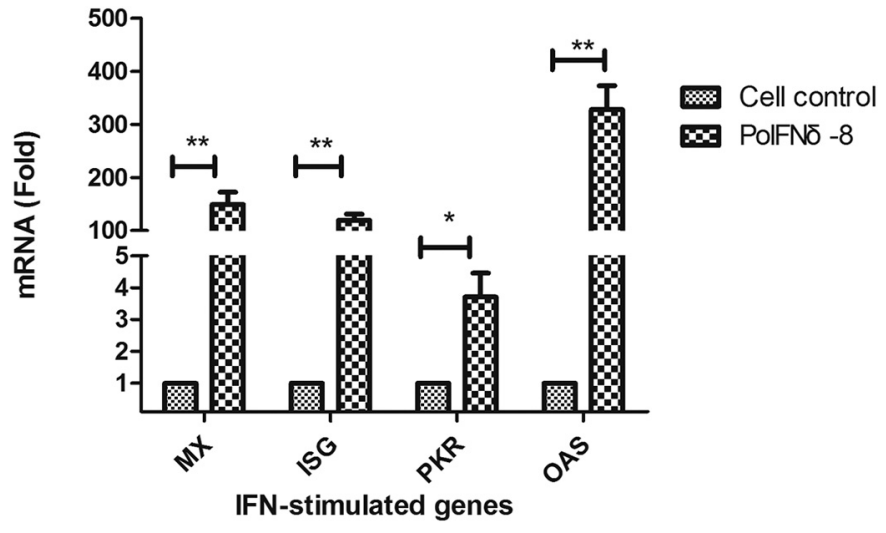

Fig. 6. Induction of expression of ISG15, Mx1, OAS and PKR by PoIFN- $\delta 8$ in IBRS-2 cells. IBRS-2 cells were treated with $2000 \mathrm{ng} / \mathrm{ml}$ of PoIFN-88. CC (cell control) indicates the non-treated IBRS-2 cells. The data were expressed as the mean fold change in gene expression \pm SEM of different PoIFN- $\delta 8$ dilutions in the IBRS-2 treated group, relative to the non-treated control group after normalization to $\beta$-actin. Data were analyzed by t-test and one way ANOVAs, followed by Tukey's post-hoc test. ${ }^{*} p<0.05,{ }^{* *} p<0.01$ compared with the non-treated control group after normalization to $\beta$-actin.

different subtypes of IFN- $\delta$ exhibit various antiviral and cross-species activity. For example, Zhao et al., [6] demonstrated that PoIFN- $\delta 8$ had the strongest antiviral and immunomodulatory activities. In this article, PoIFN- $\delta 8$ was expressed and its biological activities against FMDV was investigated. Our data demonstrated that PoIFN- $\delta 8$ had antiviral activities against FMDV. In pre-infection experiments, $2000 \mathrm{ng} / \mathrm{ml}$ of PoIFN- $\delta 8$ was the lowest concentration to provide $100 \%$ protection of IBRS-2 cells from CPE caused by infection with FMDV O/MYA98. It also provided significant protection against CPE and exhibited a 2.91-log reduction in viral RNA levels up to $8 \mathrm{~h}$ post-infection, compared to virus controls $(p<0.01)$. An increased trend in viral mRNA levels was observed from 0 to $8 \mathrm{~h}$ post-FMDV infection and elevated significantly after $8 \mathrm{~h}$. No dramatic cytopathic effects were observed during this period. In general, it takes about $8 \mathrm{~h}$ for the FMDV to replicate completely. At that, PoIFN- $\delta 8$ treatment was no longer effective in decreasing viral mRNA levels or $\mathrm{CPE}$, and caused further destruction to host cells. These results suggest that PoIFN- $\delta 8$ could be useful as an adjunct treatment during an FMD outbreak, as long as it is administered at the onset of the outbreak to protect the unaffected herd, and that the treatment is administered within $8 \mathrm{~h}$ of exposure to FMDV.

In this study, FMDV A/GD/MM/2013, a classical type A FMDV strain in our country was investigated. We found that PoIFN- $\delta 8$ could protect the cells from FMDV A/GD/MM/2013 infection, with a concentration of $1000 \mathrm{ng} / \mathrm{ml}$ needed to provide $100 \%$ protection of IBRS-2 cells. These results are comparable with the study from Usharani et al.,
[13] which showed that OvIFN- $\tau 4$ could also exhibit antiviral activities against FMDV types $\mathrm{O}$, A and Asia. These results revealed that IFNs exert their antiviral activities against a wide variety of viruses, independent of the serotype or strain challenged.

Generally, type I interferons mediate the JAK/STAT pathway to stimulate the production of antiviral effectors such as ISG genes, which interfere with different stages of viral life cycles, and inhibit viral replication or degrade viral components [17]. In this study, the expression levels of OAS1, ISG15, MX1, and PKR in PoIFN88-treated cells were significantly higher than those of the untreated cells $(p<0.01)$. Therefore, by activating the JAK-STAT signaling pathway, PoIFN- $\delta 8$ inhibited viral replication and exerted antiviral activity against FMDV.

Recently, there has been increasing interest in investigating the efficacy of combined IFN therapies, which has been shown to enhance protection, compared to single IFN therapies [15,16,18]. In future studies, it will be necessary to assess whether combining PoIFN- $\delta 8$ with other interferons (e.g., IFN- $\gamma$ ) would lead to increased efficacies against FMDV. Although the in vitro antiviral effects of IFN- $\omega$ were confirmed against FMDV, we did not confirm the in vivo activities in this study. Thus, future research is needed to investigate the efficacy of PoIFN- $\delta 8$ in animals and determine the true potential of PoIFN- $\delta 8$ as an adjunct control measure in FMD outbreaks. Such studies are also necessary to inform on the exact mechanisms leading to the biological activities of PoIFN- 88 , and explore safer, new strategies to prevent this and other diseases in pigs.

In conclusion, we demonstrated that PoIFN- $\delta 8$ exhibits antiviral activities against FMDV by inducing ISG gene expression. These findings enrich our knowledge of IFN- $\delta$, and highlight the significance of PoIFN- $\delta$ as an antiviral against FMDV.

\section{Acknowledgments}

This work was supported by the National Key Research and Development Program (2017YFD0500902), the Key R\&D Program of Gansu Province of China (Grant No. 17YF1NA070) and the National Pig Industrial System of China (CARS-36-06B).

\section{Competing interests}

The authors declare that they have no conflicts of interests.

\section{Appendix A. Supplementary data}

Supplementary data to this article can be found online at https:// doi.org/10.1016/j.intimp.2018.03.022.

\section{References}

[1] S. Pestka, C.D. Krause, M.R. Walter, Interferons, interferon-like cytokines, and their 
receptors, Immunol. Rev. 202 (2004) 8-32.

[2] F. Lefevre, V. Boulay, A novel and atypical type one interferon gene expressed by trophoblast during early pregnancy, J. Biol. Chem. 268 (1993) 19760-19768.

[3] M. Cochet, D. Vaiman, F. Lefevre, Novel interferon delta genes in mammals: cloning of one gene from the sheep, two genes expressed by the horse conceptus and discovery of related sequences in several taxa by genomic database screening, Gene 433 (2009) 88-99.

[4] F. Lefevre, M. Guillomot, S. D'Andrea, S. Battegay, C. La Bonnardiere, Interferondelta: the first member of a novel type I interferon family, Biochimie 80 (1998) 779-788.

[5] C.D. Krause, S. Pestka, Evolution of the Class 2 cytokines and receptors, and discovery of new friends and relatives, Pharmacol. Ther. 106 (2005) 299-346.

[6] X. Zhao, G. Cheng, Y. Jiao, W. Yan, M. Liu, Z. Zheng, Cloning and characterization of porcine interferon-delta-related genes identified by genomic database screening, J. Interf. Cytokine Res. 32 (2012) 378-385.

[7] Y. Sang, R.R. Rowland, R.A. Hesse, F. Blecha, Differential expression and activity of the porcine type I interferon family, Physiol. Genomics 42 (2010) 248-258.

[8] E. Perez-Martin, M. Weiss, S.F. Diaz-San, J.M. Pacheco, J. Arzt, M.J. Grubman, S.T. de Los, Bovine type III interferon significantly delays and reduces the severity of foot-and-mouth disease in cattle, J. Virol. 86 (2012) 4477-4487.

[9] E. Domingo, C. Escarmis, E. Baranowski, C.M. Ruiz-Jarabo, E. Carrillo, J.I. Nunez, F. Sobrino, Evolution of foot-and-mouth disease virus, Virus Res. 91 (2003) 47-63.

[10] N.J. Knowles, A.R. Samuel, Molecular epidemiology of foot-and-mouth disease virus, Virus Res. 91 (2003) 65-80.
[11] S.F. Diaz-San, M. Weiss, E. Perez-Martin, M.J. Koster, J. Zhu, M.J. Grubman, S.T. de Los, Antiviral activity of bovine type III interferon against foot-and-mouth disease virus, Virology 413 (2011) 283-292.

[12] F.R. Zhao, Y.L. Xie, Z.Z. Liu, J.J. Shao, S.F. Li, Y.G. Zhang, H.Y. Chang, Lithium chloride inhibits early stages of foot-and-mouth disease virus (FMDV) replication in vitro, J. Med. Virol. 89 (2017) 2041-2046.

[13] J. Usharani, S.Y. Park, E.J. Cho, C. Kim, Y.J. Ko, D. Tark, S.M. Kim, J.H. Park, K.N. Lee, M.H. Lee, H.S. Lee, Antiviral activity of ovine interferon tau 4 against footand-mouth disease virus, Antivir. Res. 143 (2017) 134-141.

[14] Y.J. Lee, C. Lee, Cytokine production in immortalized porcine alveolar macrophages infected with porcine reproductive and respiratory syndrome virus, Vet. Immunol. Immunopathol. 150 (2012) 213-220.

[15] M.P. Moraes, S.T. de Los, M. Koster, T. Turecek, H. Wang, V.G. Andreyev, M.J. Grubman, Enhanced antiviral activity against foot-and-mouth disease virus by a combination of type I and II porcine interferons, J. Virol. 81 (2007) 7124-7135.

[16] S.M. Kim, S.K. Kim, J.H. Park, K.N. Lee, Y.J. Ko, H.S. Lee, M.G. Seo, Y.K. Shin, B. Kim, A recombinant adenovirus bicistronically expressing porcine interferonalpha and interferon-gamma enhances antiviral effects against foot-and-mouth disease virus, Antivir. Res. 104 (2014) 52-58.

[17] W.M. Schneider, M.D. Chevillotte, C.M. Rice, Interferon-stimulated genes: a complex web of host defenses, Annu. Rev. Immunol. 32 (2014) 513-545.

[18] S.M. Kim, J.H. Park, K.N. Lee, S.K. Kim, Y.J. Ko, H.S. Lee, I.S. Cho, Enhanced inhibition of foot-and-mouth disease virus by combinations of porcine interferonalpha and antiviral agents, Antivir. Res. 96 (2012) 213-220. 